\title{
Credit Risk Evaluation and Management of Commercial Banks for Small and Medium Sized Enterprises
}

\author{
Yuanhong Zhao \\ SHU-UTS SILC Business School \\ Shanghai University \\ Shanghai, China \\ E-mail:374314957@qq.com
}

\author{
Xiaosong Zheng* \\ SHU-UTS SILC Business School \\ Shanghai University \\ Shanghai, China \\ E-mail: xiaosong.zheng@shu.edu.cn
}

\begin{abstract}
The credit risk management of commercial banks, as the most important outside financing channel, has significant impacts on the future development of small and medium sized enterprises (SMEs). Although there are many academic studies about the credit risk management from qualitative analysis to quantitative analysis, few specific studies are directed at the characteristics of SMEs, which makes this problem a threat to the asset quality of commercial banks. This paper reviews the evolution and current situation of credit risk management and credit strategy of commercial banks in China. Moreover, the empirical method, which is more suitable for China to measure the credit default probability of SMEs, is adopted to improve the value of the $Z$-value and the critical value is also estimated in this paper. Finally, in accordance with the credit risk evaluation and management, this paper provides some suggestions for the improvement of China's credit risk management for SMEs and innovates the risk measurement mode.
\end{abstract}

Keywords-Commercial bank; Credit risk; SME; China

\section{INTRODUCTION}

As the world's largest economic entity, the United States has been closely relevant to the development of SMEs since the 1990s. In the EU, Japan, South Korea and other countries, the number of SMEs providing employment to the society is also over $70 \%$. In Taiwan, it is even hailed as a major driving force for economic miracles. Because of its large number, wide geographical distribution, and diversified business fields, SMEs are widely regarded by economists as an important factor for a country to stabilize economic development and maintain social harmony. It is the most dynamic and development space among the main players in the market economy.

The development of enterprises is naturally inseparable from financial support. If small and medium-sized enterprises rely on their own accumulation of funds, they will be far from meeting the rapid growth situation so they must rely on the support of external financing. Although the government currently advocates the support of direct financing markets for small and medium-sized enterprises, indirect financing based on bank credit financing is still the main source of funds for SMEs.
Loan interest income is the main source of incomes for banks at the same time. The credit SMEs has become the focus of major commercial banks and the research on credit risk of SMEs has become an important part of banks to avoid risks. Throughout the world's banks, the banking crisis is the trigger of the financial crisis and the credit crisis is the main source of the banking crisis. Therefore, the credit risk assessment management of commercial banks has practical value and has always been a research topic of wide concern in the international financial community. If the credit risk management and credit evaluation mechanism of commercial banks for SMEs can be effectively improved, not only the credit risks of commercial banks can be largely resolve, but also the further development of commercial banks' financing channels for SMEs can be promoted.

This paper firstly analyzes the causes of credit risks and the current status of commercial banks' credit risk management. These analyses are based on the principles of credit informatics and credit rationing and take the requirements of the Basel New Capital Accord as a benchmark for risk management in the international banking sector. From the perspective of bank practitioners, this paper analyzes China's current credit asset quality and future credit risk assessment management mechanism based on China's macroeconomic situation.

The empirical method is used to improve the Z-value and this method establish a model which is more suitable for measuring the credit default probability of SMEs in China and to re-estimate the critical value.

\section{LITERATURE REVIEW}

Xiong (2011) stated that the information asymmetry between banks and enterprises in the market makes the bank often in the information disadvantage. Since SMEs lack transparency of the financial situations, so it is difficult for banks to track the performance of SMEs credit in the late period and this problem has become the primary target to be allocated in the credit market [1]. Also, it directly affects 
the optimal allocation of the amount of resources, not only increasing the possibility of bank loan supply loss, but also directly causing the SME's credit financing problem. The Central Bank's Research Bureau (2005) also showed that the financing needs of SMEs in China which are under the 2 million renminbi are difficult to obtain bank loan support [2]. The high risk characteristics of SMEs and the low risk appetite of banks have a large gap in credit risk which is the main reason for SMEs "Difficultly Financing"

The research on credit risk measurement model in China is mainly based on the study of the West's with improvement. Chen (1999) took 27 ST and 27 non-ST listed companies as a sample and used the single variable and multivariate discriminant analysis in the classical credit risk analysis method to obtain the flow ratio, the asset-liability ratio, the net asset return rate and the total assets yield. The four ratios have a better predictive effect and can build a discriminant function that predicts the company's financial distress [3]. Song (2000) did an empirical study on the default risk of 6 listed companies in China by using Z-value model which proved that the model had a certain applicability in the measurement of credit risk of commercial banks. Gu, Pu, and Yong (2004) had introduced the Var correction model $\mathrm{CVaR}$, and established the related credit risk measurement model. Li (2005) constructed model LOGISTC to examine the loan clients of listed companies and then concluded that the accuracy rate of the model is $83 \%$, the forecast ability reaches $80 \%$ and has higher credibility for the risk assessment of listed companies [4]. Guo (2012) pointed out that using the KMV model to measure the credit scores of the listed SMEs will affect the accuracy of the risk measurement because of the deviation of the market value of the assets and debt, so it is not suitable for China and those unlisted enterprises in the undeveloped capital markets [5].

The theoretical research on credit risks in China has been very abundant. Shen (2001) researched the new capital adequacy ratio framework and analyzed the risk sources and control of commercial Bank risk management under this framework, therefore he concluded that the determination of minimum Capital Requirement depends on three indexes: credit risk, internal rating and portfolio credit risk model. Yang, Tao, Liu (2002) established a comprehensive evaluation model of the credit status of commercial banks by using the financial ratios to reflect the liquidity, safety and profitability of the bank assets. However, it does not reflect the interplay and relationship between the three criteria that can reflect the bank's credit risk profile. Kong (2004) put forward that the previous research on credit risk control in our country paid too much attention to single factor or link, thus ignoring the complete process control of credit risk, which is one of the reasons to make our country credit risk ratio too high [6]. Duan and Wang (2008) pointed out that the defects of operation of SMEs and the imperfect of credit management system of commercial banks are the decisive factors that make up the credit risk of SMEs in the cash market [7]. Yu and Zhang (2009) believed that city commercial banks should be encouraged to exert regional advantages and establish professional SME credit platform to strengthen the whole track management of credit business. Fu (2009) argued that commercial banks should not expand blindly in the competition of SMEs credit business and they should accurately locate target customers to reduce the possibility of future default risk [8]. Zhang and He (2014) pointed out that for large state-owned or joint-stock commercial banks, improving the SME profile financing support system and credit guarantee system and gradually establishing a direct financing platform can help solve the problem of SME financing and ease the commercial bank's credit risk to SMEs [9].

To sum up, although the domestic SME credit risk researches started later, the management of commercial banks in China has been gradually standardized and mature in recent 20 years, and the risk management industry has been paid more and more attention. As the supervision of China's banking industry is getting close to international standards, the knowledge of risk management of commercial banks suggested by the Basel New Capital Accord has also begun to promote in the Chinese banks, increasing the risk management of China's commercial banks constraints. The management of credit risk in China has gradually shifted from qualitative assessment to more accurate quantitative evaluation. However, the application of risk measurement model is limited due to the lack of historical data in our capital market, and the loan default rate is mainly based on large enterprises. The establishment of the model for small and medium-sized enterprises is still awaiting further studies.

\section{THE CURRENT SUITATION AND DEFICIENCIES OF CREDIT RISK MANAGEMENT OF CHINA'S COMMERCIAL BANKS}

There are many factors that affect credit risks. SMEs have many differences in their business scale and management model, and the reasons for credit risk are also unique. The causes of credit risk of SMEs can be basically divided into three categories: the management problems of banks themselves, the defects of SMEs and the macroeconomic factors of society.

The inherent problems of commercial banks have also increased dangers to the occurrence of credit risk. Firstly, the government's intervention in banking management is still very large so it is difficult for banks to conduct business through the commercial needs of the market economy. The overall quality of the employees of the city commercial bank and the experience of handling the business usually need to be improved. In addition to, some banks' performance appraisal systems are also the cause of frequent credit risks. In the process of pre-lending investigations, the loan officers only pay attention to the investigation of written materials such as financial statements, which has great risks and limitations.

Commercial banks' pre-lending review and post-lending management for SMEs are also much more difficult than for large companies. Some enterprises have weak credit awareness and often use fraudulent financial statements and asset certificates to defraud bank loans. The moral hazard generated by this information asymmetry greatly increases the cost of bank information collection and screening work, so it also poses a great risk possibility for banks to issue loans to SMEs.

The domestic legal system is not sound enough and the development of economic activities often lacks the protection with an effective legal system. Especially for SMEs enterprises 
with low morality, malicious defrauding, default payment and other actions are not well disciplinary measures. The lack of legal restraint does not constrain the lending and borrowing behavior of SMEs well. The accumulation of bad credit in banks will worsen the quality of assets and thus create huge credit risks.

\section{RESEARCH DATA AND METHOD}

\section{A. Improve the suitable risk assessment model for China}

Compared with the quantitative analysis which is emphasized by the Basel New Capital Accord, the risk assessment in our country is mainly based on the qualitative method of subjective judgment and the way of rating is too simple. At present, many commercial banks' risk ratings in our country are still in the stage of scoring card of expert scoring. To steadily improve the level of credit risk management in China, we must learn from the mature risk measurement research in the United States. However, the application of KMV and Credit Metrics models in China's commercial banks, especially for SMEs has been greatly limited. The KMV model belongs to the advanced model of credit risk measurement, which is based on the mature capital market of western developed countries and mainly aims at the listed enterprises. The basic idea is to obtain the expected default probability (EDF) by analyzing the change of the stock market value of the credit enterprise, however, most of the enterprises in China are not listed, and the development degree of the capital market is far from the developed country's level, so it is difficult to use the model directly to measure. Moreover, the Credit Metrics model the measurement of the enterprise credibility risk mainly from the change of the credit rating of the enterprise needs a lot of historical data as the basis, at present our bank's data reserves, especially the small and medium-sized data is not very good to be applied to the model in the terms of quality and quantity [10].

Comparatively speaking, using financial data to evaluate the expected default rate of SMEs is more suitable for the current development of SME credit business in China. If we can choose more appropriate financial index and critical value though the actual situations of SMEs in China, we can establish the Z-value method in accord with the characteristics of SMEs in our country. Therefore, the model can be more accurate to evaluate the default probability of enterprises.

Wang and Han use the empirical method to select the key indexes for predicting the maturity repayment ability of Chinese enterprises in many financial indexes which is based on variable selection method of neural network. On the basis of considering the financial ratios used in previous financial crisis early warning studies, 10 financial ratios were initially selected in reference to the 5 financial ratios selected by Altman for the Z-value method: net profit margin, return on total assets, return on equity, current ratio, acid test ratio, asset-liability ratio, debtequity ratio, asset turnover, accounts receivable turnover and inventory turnover. According to the empirical studies on the Shanghai and Shenzhen stock Market ST Companies (that are warned specially in withdrawal risks), the paper chooses the data of the enterprise the year before the loss to warn the company ST and Non-ST states. Empirical samples are selected from the Shanghai and Shenzhen Stock Exchange 43 Companies and the financial ratios are selected respective company annual report. Finally, the results of the measurement as shown in table 1.1 by MATLAB [11].

It can be concluded from the table 1 that the sum of the return on total assets, return on equity, current ratio, assetliability ratio and asset turnover ratio selection coefficient accounts for $95.37 \%$ in total 10 ratios, so they have a significant impact on the possibility of financial crisis. They can be used as explanatory variables in the response to financial risk warning model and the 5 financial ratios are also fully reflected in the profitability, solvency and operational capability of the enterprise. At the same time, the 5 other financial ratios have little influence on the possibility of financial crisis and can be neglected. According to this research, we can build a new Z-value model based on Chinese enterprise characteristics by using these 5 financial ratios and their correlation coefficients:

$\mathrm{Z}=0.365 \times$ Total Assets Profit Rate $+0.851 \times$ Return on Net Assets $+0.063 \times$ Flow Ratio $+0.166 \times$ Asset -

Liability Ratio $-0.423 \times$ asset turnover rate

TABLE I. FINANCIAL RATIOS PERCENTAGE

\begin{tabular}{|c|l|l|l|l|l|}
\hline & \multicolumn{1}{|c|}{ Debt-equity ratio } & \multicolumn{1}{|c|}{ Return on total assets } & \multicolumn{1}{|c|}{ Return on equity } & Current ratio & \multicolumn{1}{c|}{ Acid test ratio } \\
\hline Selectivity coefficient & 0.0315 & 0.3658 & 0.8510 & 0.0625 & -0.0087 \\
\hline Percentage & $1.61 \%$ & $18.67 \%$ & $43.44 \%$ & $3.19 \%$ & $0.44 \%$ \\
\hline & Asset-liability ratio & Total asset turnover & $\begin{array}{l}\text { Accounts receivable } \\
\text { turnover }\end{array}$ & $\begin{array}{l}\text { Inventory } \\
\text { turnover }\end{array}$ & Net profit margin \\
\hline Selectivity coefficient & 0.1660 & -0.4233 & 0.0015 & 0.0013 & -0.0476 \\
\hline Percentage & $8.47 \%$ & $21.6 \%$ & $0.07 \%$ & $0.07 \%$ & $2.43 \%$ \\
\hline
\end{tabular}

Source: Wang \& Han [11]. 


\section{B. Determine the Critical Value Z}

The abnormal conditions of the ST Enterprises in China usually include abnormal financial situation and abnormal operating conditions, and these anomalies are important factors that affect the repayment ability of enterprises so the bank will not make credit decision. If we can find out whether the Z- value and SMEs which are judged ST in our country can establish the relationship, then it can find out the Z-value and the critical Z-value which is suitable for assessing the default probability of SMEs. Therefore, the paper selects the enterprises listed in Shanghai and Shenzhen as empirical samples and select the financial data in 2014, to determine the critical Z-value which is more suitable for China.

TABLE II. ENTERPRISES ST AND Z-VALUE MAPPING RELATIONSHIP

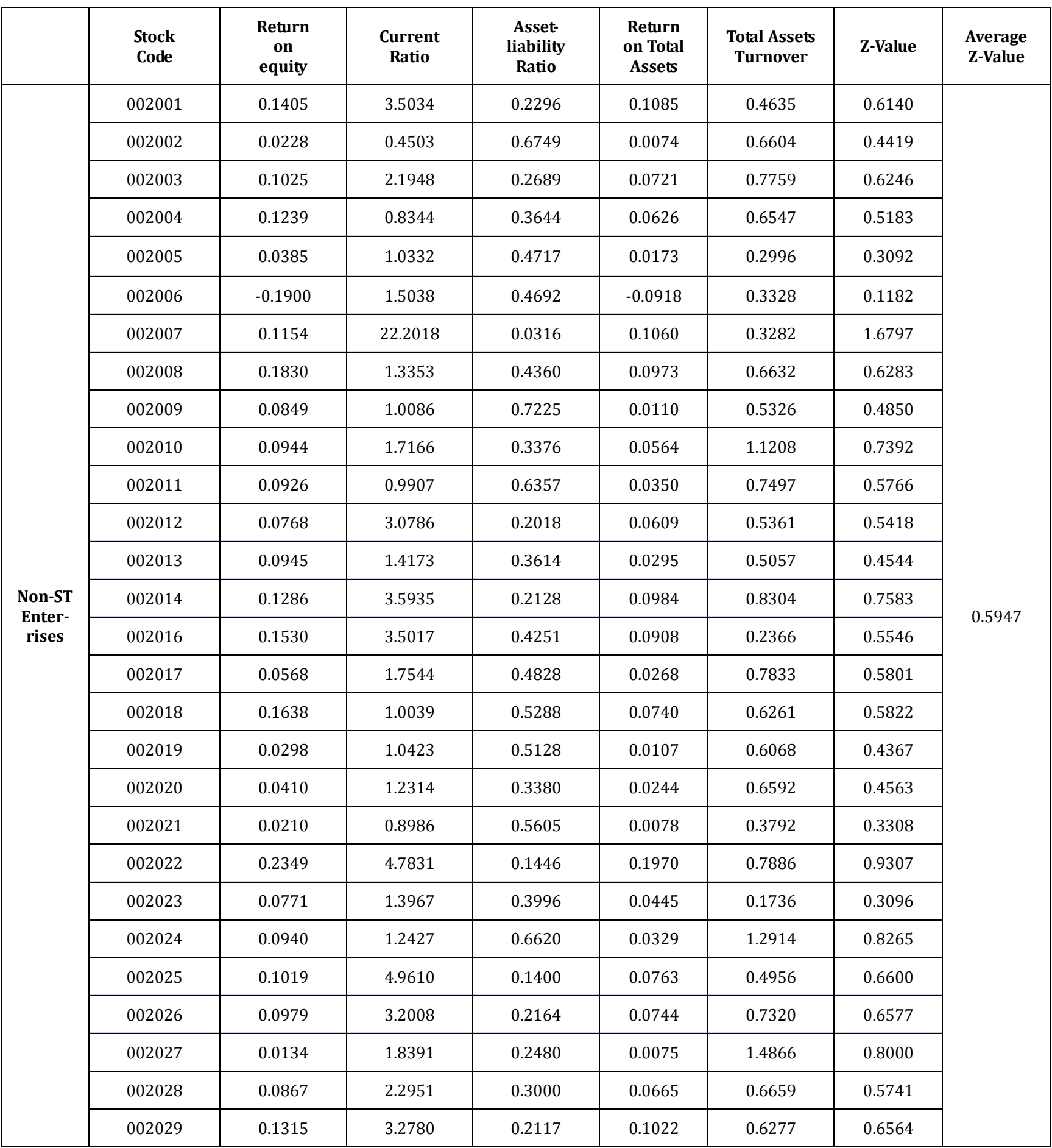




\begin{tabular}{|c|c|c|c|c|c|c|c|c|}
\hline & \multicolumn{7}{|c|}{ Table II, cont } & \\
\hline & 002030 & 0.1573 & 1.8997 & 0.3102 & 0.0942 & 0.6387 & 0.6096 & \\
\hline & 002031 & 0.0812 & 1.5707 & 0.4880 & 0.0415 & 0.2881 & 0.3861 & \\
\hline \multirow{10}{*}{$\begin{array}{c}\text { ST } \\
\text { Enterpri } \\
\text { ses }\end{array}$} & 002015 & 0.0093 & 0.2268 & 0.9162 & -1.0422 & 0.4109 & -0.0323 & \multirow{10}{*}{-0.5031} \\
\hline & 002192 & 0.0157 & 0.6362 & 0.9628 & -0.1635 & 0.3687 & 0.3095 & \\
\hline & 002306 & 0.0871 & 0.9783 & 0.4975 & -1.1498 & 0.2794 & -0.0831 & \\
\hline & 002417 & 0.0393 & 0.3782 & 0.6061 & -0.6370 & 0.3579 & 0.0768 & \\
\hline & 002506 & -0.8481 & 1.0101 & 0.8958 & -0.6492 & 0.3563 & -0.5957 & \\
\hline & 002608 & 0.0402 & 0.7286 & 0.9772 & -0.6017 & 0.4637 & 0.2188 & \\
\hline & 002633 & 0.0111 & 0.3729 & 0.4188 & -0.1407 & 0.2829 & 0.1708 & \\
\hline & 000594 & -0.0145 & 1.4977 & 0.2760 & 1.2561 & 0.0019 & 0.5871 & \\
\hline & 600247 & 0.0444 & 0.8885 & 0.5212 & -15.3294 & 0.0251 & -5.4043 & \\
\hline & 600656 & 0.3302 & 0.0391 & 0.9431 & -2.0317 & 0.0539 & -0.2788 & \\
\hline
\end{tabular}

Based on the above results from table 2, we can make the following judgments:

When $z>0.5974$, we can basically think that the company's financial situation and operating conditions are good, the banks can credit with consideration.

When $z<-0.5031$, the company's operating and financial situation has been the vigilance of regulatory investors and future solvency cannot be guaranteed. Do not recommend banks to lend due to the company's higher level of credit risk.

When $-0.5031<\mathrm{z}<0.5974$, banks need to further audit the enterprise to decide whether grant the credit.

Although the data is limited and the accuracy of the critical value is still to be improved, the model is relatively simple for the data requirements and the feasibility of SMEs is relatively strong, so it can make a basic judgment on the degree of credit risk.

\section{Improve credit rating method and 5-class classification of loans}

SMEs and large enterprises have a lot of differences in the scale of operation, profitability, assets operating capacity and other aspects, small. Moreover, interest rate marketization process, medium-sized enterprises financial fraud, regional risk differences and some other actual factors also should be taken into consideration. The credit rating of different scale should be in more detailed classification, so it is useful to make more accurate judgment on the enterprise credit situation. At present, China's credit asset five-class classification standards lay emphasis too much on qualitative description and too less on quantitative analysis, so it is easily affected by subjective factors. Moreover, risk division and induction are also relatively general. If the five types of loans can be divided more in detail and set the measurement standards, it can improve the objectivity of the classification results. At present, ICBC is operating 10-level credit division system for SMEs which is well worthy of use by other commercial banks [12]. The improvement of the standard of credit rating mechanism and loan category can improve the management level of credit risk of commercial banks to a great extent.

\section{Build the completed SMEs credit system}

The continuous improvement and development of the credit system in China is an important force for pushing the healthy development of the SMEs. The government needs to stimulate SMEs to improve their financial and managerial levels and information transparency from different perspectives, such as finance and taxation, while encouraging third parties to transfer credit risk of some commercial banks under appropriate conditions to guarantee SME credit. From the experience of the United States, China can also divide the SME guarantee institutions into national security and provincial security [13]. SME credit guarantee institutions rely on the reinsurance system to disperse the risk of the enterprise, and the security agencies carry out second risk sharing for guarantee institutions by preferential rate to support the guarantee institutions to expand the scope of security and improve the level of SME credit financing services.

\section{CONCLUSIONS}

We can draw the conclusion that China's credit risk management started late, so far most are based on the qualitative theoretical analysis. Western developed countries, especially the United States is our main learning object, but the development of credit risk management level is also a step-bystep process which cannot be accomplished overnight. The development of China's capital market is still immature and the historical database of enterprise credit business is not perfect, so the blind reference cannot effectively help our commercial banks to improve the risk management level. At present, China should combine the guidance of the Basel New Capital Accord on credit risk management and China's national conditions to improve the use of the basic risk measurement model from the financial data and continue to develop the advanced econometric model and credit strategy which is more suitable for our market with the continuous development of financial market.

In this way, we can really improve our credit risk management ability and gradually connect with the developed countries. Most importantly, credit risk management mechanisms should not only be piecemeal measurement methods and qualitative criteria. Commercial banks should set up a complete credit risk control system for SMEs and pay 
attention to loan credit evaluation and credit pricing, project tracking in loan, risk audit after credit and loan recovery to realize the whole process of credit risk.

In addition, the Government should provide standard SME credit guarantee platform to share a part of credit risk, and reasonably control the increase of non-performing loan assets of commercial banks. In recent years, the credit risk management mechanism of SMEs in commercial banks has made obvious progress. The future research direction will mainly focus on the study of the risk measurement model and continue the transformation from qualitative analysis to quantitative analysis of credit risk management in China. At the same time, it still takes the Basel New Accord as the guidance to accelerate the establishment of SME credit rating system.

\section{REFERENCES}

[1] Z. Xiong, "Study on credit financing constraints of SMEs and their countermeasures--from the perspective of asymmetric information, Bank and Enterprise Credit, 2011.

[2] Central Bank Research Bureau, "Investigation Report on the financial system of Chinese Small and medium-sized enterprises", Economic Guide, vol. 4, pp.12-23, 2005.

[3] J. Chen, "Empirical analysis of financial deterioration prediction of listed companies", Accounting Studies, 1999.

[4] Y. Li, "Research on credit risk management of small and medium-sized enterprises in Chinese commercial banks", Southwest University of Finance and Economics, 2012.

[5] X. Guo, "Research on credit risk measurement of SMEs in China", Nankai University, 2012.

[6] X. Zhou, "Comparison and analysis of credit models of modern commercial banks", Southwest University of Finance and Economics, 2007.

[7] B. Duan and Z. Wang, "Research on credit risk management of small and medium-sized enterprises in joint-stock commercial banks", Financial Securities, 2008.

[8] Z. Fu, "Research on credit risk in small and medium-sized enterprises in commercial prevention", Economist, 2009.

[9] F. Zhang and He. Hong, "Analysis and revelation of domestic and foreign SMEs”, ICASS, 2014.

[10] Z. Yin, "Application of credit measurement model in credit risk management of small and medium-sized enterprises", Central university of Finance and Economics, 2008.

[11] J. Wang and W. Han, "Research on the selection of financial ratios in financial warning", Mathematics practice and understanding, 2003.

[12] Y. Yang, "Research on credit risk measurement of Chinese SMEs", Finance Forum, 2009.

[13] Z. Wang and G. Zhou, "Research on credit risk sharing mechanism of small and medium-sized enterprises", Journal of Tianjin Normal University (social Science Edition), 2011. 